\title{
Induced Abortion: a Systematic Review and Meta-analysis
}

\author{
Saeed Dastgiri' ${ }^{1}$ Maryam Yoosefian², Mehraveh Garjani², Leila R Kalankesh ${ }^{3,4}$
}

School of Medicine, Tabriz University of Medical Sciences, Tabriz, Iran

${ }^{2}$ Road Traffic Injury Research Center, Tabriz University of Medical Sciences, Tabriz, Iran ${ }^{3}$ School of Management and Medical Informatics, Tabriz University of Medical Sciences

4Tabriz Health Services Management Research Center, Tabriz University of Medical Sciences

Corresponding author: Dr Leila R Kalankesh, School of Management and Medical Informatics, Tabriz University of Medical Sciences, Daneshgah Ave, Tabriz, Iran, Postal Code: 5166614711, E-mail: Irkalankesh@tbzmed. ac.ir

\section{ABSTRACT}

Background: Induced abortion accounts for 1 in 8 of approximately 600000 maternal deaths that occur annually worldwide. Induced abortion rate can be considered as one of the indicators for assessing availability of the appropriate reproductive health plans for women and identifying needs for appropriate related health policies and programs. Material and Methods: Researchers searched Pubmed, Google Scholar, CINAHL, Embase, PsycINFO, Cochrane, Iranian Scientific Information Database (SID), Iranian biomedical journals (Iranmedex), and Iranian Research Institute of Information and Documentation (Irandoc) between January 2000 and June 2013, which reported induced abortion. Search terms from two categories including abortion and termination of pregnancy were compiled. The search terms were "induced abortion" , "illegal abortion", "illegal abortion", "unsafe abortion", and "criminal abortion". The search was also conducted with "induced termination of pregnancy" ,"illegal termination of pregnancy"," illegal termination of pregnancy", "unsafe termination of pregnancy" and "criminal termination of pregnancy" . Meta-analysis was carried out by using OpenMeta software. Induced abortion rates were calculated based on the random effect model. Results: Overall induced abortion rate was obtained 58.1 per 1000 women ( $95 \% \mathrm{Cl}: 55.16-61.04)$. In continental level, rate of induced abortion was 14 per 1000 women $(95 \% \mathrm{Cl}$ : 11-16). Nation-wide and local rates were obtained 67.27 per 1000 women (95\% Cl: 60.02-74.23) and 148.92 (95\% Cl: 140.06-157.79) respectively. Discussion and Conclusion: Induced abortion is a major public health problem that occurs worldwide whether under the legal restriction or freedom, and it remains as reproductive health concern globally. To eliminate the need for induced abortion is at the core of any effort for preventing this issue. Option with the highest priority is to prevent unwanted pregnancies through promoting reproductive health plans for women of reproductive age. In case the prevention strategies fail, universal provision of safe abortion services should be put in place.

Keywords: Induced Abortion, systematic review, meta-analysis.

\section{INTRODUCTION}

Induced abortion accounts for 1 in 8 of approximately 600000 maternal deaths that occur annually worldwide $(1,2)$.

According to the WHO estimation, each year about 44 million induced abortions occur globally. About fifty percent of these abortions are unsafe, contributing substantially to maternal morbidity and approximately leading to $13 \%$ of maternal mortality $(3,4)$.

The induced abortion rate varies considerably. It was approximated 12 per 1000 women aged 1544 years old in Western Europe, comparing to 43 in Eastern Europe (5). The induced abortion rate is even higher in countries like Uganda, where there were 54 induced abortions per 1000 women in 2003 (6). Evidence shows the induced abortions are more likely in countries in which abortion is illegal or restricted compared to those liberated (5). The majority ( $98 \%$ ) of unsafe abortions occur in developing countries with low level socio-economic state $(1,4,7)$. Induced abortion rate can be considered as one of the indicators for assessing availability of the appropriate reproductive health plans for women (5) and to identify needs for appropriate related health policies and programs (1). Aim of this study is to conduct a systematic review and meta-analysis on induced abortion rate worldwide.

\section{METHODS}

\section{Inclusion criteria and search strategies}

We searched PubMed, Google Scholar, CINAHL, Embase, PsycINFO, Cochrane, Iranian Scientific Information Database (SID), Iranian biomedical journals (Iranmedex), and Iranian Re- 
search Institute of Information and Documentation (Irandoc) between January 2000 and June 2013, which reported induced abortion. We compiled search terms from two categories including abortion and termination of pregnancy. The search terms were "induced abortion”, "illegal abortion”, "illegal abortion”, "unsafe abortion”, and "criminal abortion”. The search was also conducted with "induced termination of pregnancy”, ,illegal termination of pregnancy”, “unsafe termination of pregnancy" and "criminal termination of pregnancy". Results from the query were restricted to the publications in English and Farsi. Three reviewers independently screened the titles and abstracts of the retrieved papers to decide if they met the inclusion criteria for the meta-analysis. Any disagreement was resolved through consultation with the principal researcher. The form with predefined items was prepared and used for extracting data from the studies while reviewing the full text of the eligible studies. To be eligible for inclusion, the study had to report the abortion cases per pregnant women. The data collected for the analysis included: author name, study location, period of study, age range of the participants, the number of induced abortions, sample size, and confidence interval of the study.

We used the STROBE checklist to assess the quality of the studies. Studies evaluated as low quality were excluded from the systematic review and meta-analysis.

Heterogeneity of the studies was determined through deploying the Cochrane test $(\mathrm{p}<0.05)$ and quantified by $\mathrm{I}^{2}$ statistic. Meta-analysis was carried out by using OpenMeta (8) version 12.11.14 which is completely open-source and cross platform software for advanced meta-analysis. Considering the heterogeneity of the studies, the random effect model (confidence interval=95\%) was applied for the analysis.

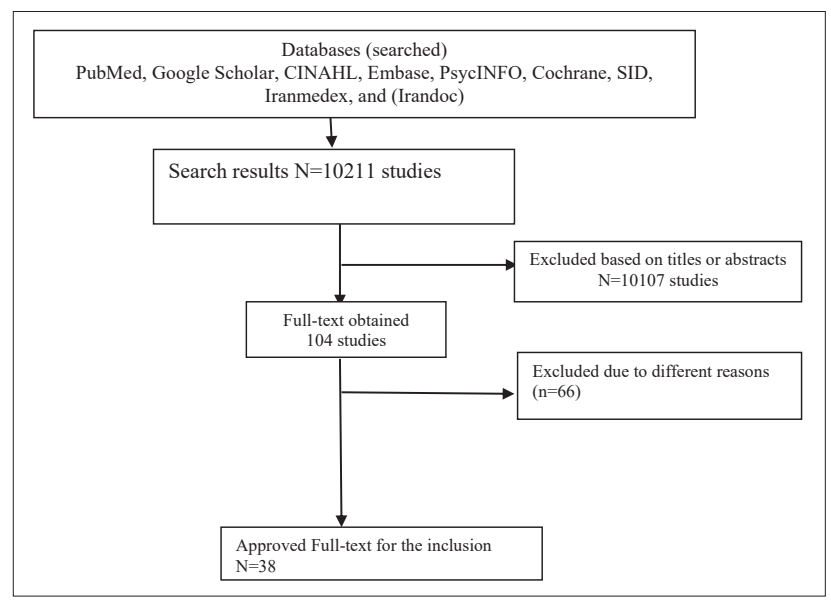

Figure 1. Flowchart of study selection

\section{RESULTS}

\section{Description of studies}

A total number of 38 studies were considered as a final list for the systematic review and meta-analysis. A total number of 67 statistics on induced abortion rate were extracted from the included studies. Sample size of studies was varied ranging from 43 to 1542857143 . This variation was due to the various levels of the studies ranging from local level to the global scale. Table 1 shows induced abortion rates worldwide, nationwide and in the regional level.

I: to save the women life or prohibited altogether II: to preserve health III: Socioeconomic grounds IV: without re- striction as to reason

\section{Induced abortion rates in different levels}

Abortion rate reported in the included studies ranged from 0.04 to 674.4 .4 per 1000 the studied women. The lowest rate belongs to South Korea while the highest one is from Pakistan.

As it can be seen in Table 1, abortion rates are from different geographic levels including global, continental, national, regional or local levels. Four rates for induced abortion had been reported in global level. Twenty-one statistics had been related to continental level. Nineteen rates were reported on national level and 23 of them were in regional or local level. The remainders are in global level.

Majority of national rates ( $47 \%$ ) belonged to the countries from Asia, followed by Africa (26\%). There was only one statistic reported from European country, Romania, in national level. About 61 percent of the statistics reported in local or regional level were related to Asia, followed by those from Africa (21\%) and Latin America (13\%).

\section{Overall meta-analysis of induced abortion rates}

Figure 2 shows the results of meta-analysis conduced on all statisctics extracted from the studies. Overall abortion rate was 58.1 per 1000 women ( $95 \% \mathrm{CI}$ : 55.16-61.04). The lowest rate is related to the world in 2000, the second lowest one belongs to Vietnam and the third lowest rate belong to Indonesia.

Meta-analysis of induced abortion rates in different continents

Based on the random effect model, the overall abortion rate was 14 per 1000 fertile women, 95\% CI (11 to 16). Substantial between-study heterogeneity was observed $(\mathrm{Q}=36221823.84$, $\mathrm{df}=20, \mathrm{I}^{2}=10000, \mathrm{p}$-value $\left.<0.001\right)$. Conducting Leave-one-out meta-analysis confirmed the validity and robustness of the meta-analysis. Figure 3 shows the result of this meta-analysis.

Meta-analysis of induced abortion rates in the national and local rates

As Figure 4 presents induced abortion rates for the local, regional and national levels were pooled from all 42 statistics and the summary rate of 101 per 1000 fertile women was obtained ( $\mathrm{CI}=95 \%$ : 95-106 per 1000 fertile women). Cochrane's test shows high heterogeneity of the included studies $\left(\mathrm{Q}=7028315, \mathrm{df}=41, \mathrm{I}^{2}=99.99, \mathrm{p}\right.$-value $\left.<0.001\right)$. Conducting one-leave-out meta-analysis also confirmed a large amount of heterogeneity.

Meta-analysis of induced abortion rates in different countries

Based on the random effect model, the overall abortion rate in national levels was 67.27 per 1000 fertile women (CI $=95 \%: 60.02$ to 74.53$)$. High heterogeneity was observed among studies $\left(\mathrm{Q}=6992326, \mathrm{df}=18, \mathrm{I}^{2}=99.999, \mathrm{p}\right.$-value $\left.<0.0001\right)$. The validity and robustness of the meta-analysis was confirmed as the summary rate remained same after applying leave one out meta-analysis. Figure 5 shows the result of this meta-analysis.

Meta-analysis of induced abortion rates in different regions or cities

Based on the random effect model, the overall induced abortion rate in regional or local level was 148.92 per 1000 fertile women, 95\% CI (140.06 to 157.79). High heterogeneity was observed among studies $\left(\mathrm{Q}=25024.027, \mathrm{df}=22, \mathrm{I}^{2}=99.91\right.$, $\mathrm{p}$-value<0.001). Applying leave-one -out method of metaanalysis confirmed the result. Figure 6 shows the result of 


\begin{tabular}{|c|c|c|c|c|c|c|c|c|c|}
\hline 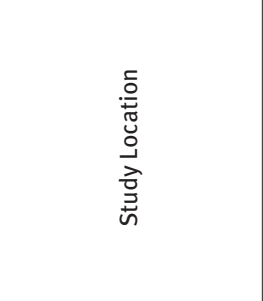 & 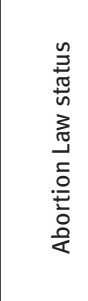 & 莣 & 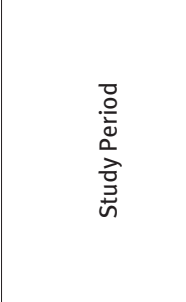 & 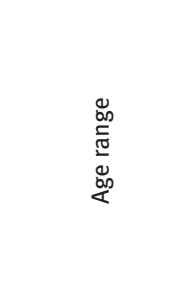 & 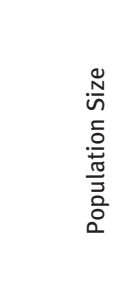 & 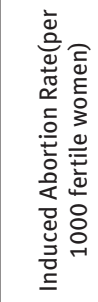 & 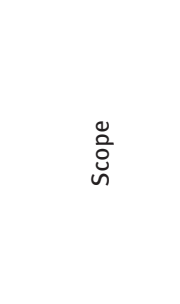 & $\begin{array}{l}\bar{\Xi} \\
\overline{0} \\
\vdots \\
0\end{array}$ & $\begin{array}{l}\bar{U} \\
\frac{1}{0} \\
\frac{0}{0}\end{array}$ \\
\hline Rwanda (7) & II & AF & 2009 & $15-44$ & 2407652 & 25.04 & National & 24.8 & 25.23 \\
\hline Mexico(9) & 1 & LA & 1999-2006 & $15-44$ & 26515152 & 33 & National & 32.9 & 33.1 \\
\hline Peru(10) & II & LA & 2005(Sep-Dec) & $18-29$ & 7992 & 116.12 & National & 109 & 123 \\
\hline Ethiopia(11) & II & AF & 2008 & $15-44$ & 16608696 & 23 & National & 22.9 & 23.07 \\
\hline Pakistan-1(12) & II & AS & 2002 & $15-49$ & 30689655 & 29 & National & 28.9 & 29.06 \\
\hline Guatemala-1(13) & 1 & LA & 2003 & $15-49$ & 2708333 & 24 & National & 23.8 & 24.18 \\
\hline Uganda-1(6) & 1 & AF & 2003 & $15-49$ & 5500000 & 54.1 & National & 53.81 & 54.19 \\
\hline Philippines(14) & 1 & AS & 2000 & $15-44$ & 17533333 & 27 & National & 26.92 & 27.08 \\
\hline Burkina Faso(15) & II & AF & 2008 & $15-49$ & 3488000 & 25 & National & 24.84 & 25.16 \\
\hline South Korea(16) & II & AS & 2005 & $15-44$ & 11491040 & 0.04 & National & 0.03 & 0.05 \\
\hline Vietnam(17) & IV & AS & 2001 & $15-49$ & 27097 & 400 & National & 394 & 406 \\
\hline Romania(18) & IV & EU & 2001 & $15-49$ & 500 & 32 & National & 16.6 & 47.43 \\
\hline Cambodia(19) & IV & AS & 2005 & $16-53$ & 3644327 & 8.6 & National & 8.5 & 8.7 \\
\hline Indonesia(20) & 1 & AS & 2000 & $15-49$ & 54054054 & 366.7 & National & 366.3 & 367.1 \\
\hline Uganda-2(21) & 1 & $\mathrm{AF}$ & 2002 & $15-44$ & 5182926 & 16.4 & National & 16.3 & 16.5 \\
\hline Pakistan-2(21) & II & AS & 2002 & $15-44$ & 28142857 & 7 & National & 6.97 & 7.03 \\
\hline Guatemala-2(21) & 1 & LA & 2003 & $15-44$ & 2511627 & 86 & National & 85.65 & $86-35$ \\
\hline Philippines(21) & I & AS & 2000 & $15-44$ & 17761363 & 4.4 & National & 4.37 & 4.43 \\
\hline $\operatorname{Iran}(22)$ & 1 & AS & 2000 & $15-49$ & 9760000 & 7.47 & National & 3.135 & 6.406 \\
\hline Abbottabad(23) & II & AS & $2006-2007$ & $20-45$ & 1090 & 47.7 & Local/Regional & 35.05 & 60.36 \\
\hline $\begin{array}{l}\text { Bavi district in } \\
\text { Vietnam(24) }\end{array}$ & IV & AS & 1999-2004 & $15-44$ & 5259 & 139.4 & Local/Regional & 130.02 & 148.74 \\
\hline Athens- Greece(25) & IV & EU & $2005-2008$ & Above 39 years & 163 & 380.37 & Local/Regional & 305.84 & 454.9 \\
\hline Edo State- Nigeria(26) & 1 & $\mathrm{AF}$ & 2002 & $15-24$ & 601 & 409.32 & Local/Regional & 370.01 & 448.63 \\
\hline $\begin{array}{l}\text { Berekum District- } \\
\text { Ghana(27) }\end{array}$ & II & AF & 1999(Jan-Feb) & $15-49$ & 1685 & 473.59 & Local/Regional & 449.75 & 497.43 \\
\hline Rural South India(28) & III & AS & 1996 & $15-45$ & 283 & 183.75 & Local/Regional & 138.62 & 228.87 \\
\hline $\begin{array}{l}\text { Kargera Region(Urban)- } \\
\text { Tanzania(29) }\end{array}$ & 1 & $\mathrm{AF}$ & 2006 & Under 24 years & 473 & 625.79 & Local/Regional & 582 & 669.4 \\
\hline $\begin{array}{l}\text { Temeke Municipal } \\
\text { Hospital(Rural)- } \\
\text { Tanzania(29) }\end{array}$ & 1 & AF & 2003 & Under 24 years & 278 & 622.3 & Local/Regional & 565.3 & 679.2 \\
\hline $\begin{array}{l}\text { Bahawalpur- } \\
\text { Pakistan(30) }\end{array}$ & II & AS & 2008 & $15-44$ & 2500 & 8.4 & Local/Regional & 5 & 12 \\
\hline $\begin{array}{l}\text { Hyderabad- } \\
\text { Pakistan(31) }\end{array}$ & II & AS & $\begin{array}{l}\text { 2008(March)- } \\
\text { 2009(Feb) }\end{array}$ & $15-44$ & 230 & 217.4 & Local/Regional & 164.1 & 270.7 \\
\hline Lusaka-Zambia(32) & III & AF & $\begin{array}{l}\text { 2005(4-month } \\
\text { period) }\end{array}$ & $13-19$ & 87 & 390.8 & Local/Regional & 288.3 & 493.3 \\
\hline $\begin{array}{l}\text { Cartagena- } \\
\text { Columbia(33) }\end{array}$ & II & LA & 2005 & $15-44$ & 9950 & 221.2 & Local/Regional & 213.05 & 229.36 \\
\hline $\begin{array}{l}\text { Cartagena- } \\
\text { Columbia(33) }\end{array}$ & II & LA & 2006 & $15-44$ & 9509 & 221 & Local/Regional & 213 & 229 \\
\hline $\begin{array}{l}\text { Cartagena- } \\
\text { Columbia(33) }\end{array}$ & II & LA & 2007 & $15-44$ & 9377 & 209.9 & Local/Regional & 201.7 & 218.2 \\
\hline Karachi- Pakistan(34) & II & AS & 2005-2009 & $18-42$ & 43 & 674.4 & Local/Regional & 534.4 & 814.4 \\
\hline
\end{tabular}




\begin{tabular}{|c|c|c|c|c|c|c|c|c|c|}
\hline Tehran, Iran(35) & 1 & AS & 2008 & $15-44$ & 2098790 & 5.49 & Local/Regional & 5.39 & 5.59 \\
\hline Tehran, Iran(36) & 1 & AS & $\begin{array}{l}\text { July } 2003-\text { Jan } \\
2004\end{array}$ & $15-55$ & 2470 & 94.33 & Local/Regional & 83 & 106.9 \\
\hline Tehran, Iran(35) & 1 & AS & 2009 & $15-44$ & 2934 & 5.45 & Local/Regional & 2.78 & 8.11 \\
\hline Isfahan, Iran(37) & 1 & AS & 2003-2004 & $15-50$ & 417 & 119.9 & Local/Regional & 88.72 & 15.11 \\
\hline Shiraz, Iran(38) & 1 & AS & 2001 & $15-49$ & 550 & 29.09 & Local/Regional & 15.04 & 43.13 \\
\hline Kermanshah, Iran(39) & 1 & AS & 2004 & NOS & 11206 & 1.34 & Local/Regional & 0.66 & 2.01 \\
\hline Tehran, Iran(40) & 1 & AS & 1991-1995 & 102 & 1115 & 91.4 & Local/Regional & 74.5 & 108.4 \\
\hline Kermanshah, Iran(41) & 1 & AS & 1992-2002 & NOS & 205250 & 64.99 & Local/Regional & 63.9 & 66.06 \\
\hline Africa-1(1) & \begin{tabular}{|l|} 
Mostly \\
I,II, \\
Some \\
III,IV \\
\end{tabular} & - & 2003 & $15-44$ & 189655172 & 29 & Continental & 28.9 & 29.02 \\
\hline Asia-1(1) & I,II,III,IV & - & 2003 & $15-44$ & 890909091 & 11 & Continental & 10.9 & 11.01 \\
\hline Europe-1(1) & \begin{tabular}{|l|} 
Mostly IV \\
Some III \\
and II \\
\end{tabular} & - & 2003 & $15-44$ & 166666667 & 3 & Continental & 2.99 & 3.01 \\
\hline Latin America-1(1) & $\begin{array}{l}\text { I,II } \\
\text { Few IV }\end{array}$ & - & 2003 & $15-44$ & 134482759 & 29 & Continental & 28.9 & 29.03 \\
\hline North America-1(1) & IV & - & 2003 & $15-44$ & 71428759 & 0.7 & Continental & 0.69 & 0.71 \\
\hline Oceania-1(1) & IV & - & 2003 & $15-44$ & 6666667 & 3 & Continental & 2.9 & 3.04 \\
\hline Africa-2(42) & \begin{tabular}{|l|} 
Mostly \\
I,II, some \\
III,IV
\end{tabular} & - & 2000 & $15-44$ & 190909091 & 22 & Continental & 21.98 & 22.02 \\
\hline Asia-2(42) & I,II,III,IV & - & 2000 & $15-44$ & 954545455 & 11 & Continental & 10.99 & 11.01 \\
\hline Europe-2(42) & \begin{tabular}{|l|} 
Mostly IV \\
Some III \\
and II
\end{tabular} & - & 2000 & $15-44$ & 166666667 & 3 & Continental & 2.99 & 3.01 \\
\hline Latin America-2(42) & $\begin{array}{l}\text { I,II, Few } \\
\text { IV }\end{array}$ & - & 2000 & $15-44$ & 142307692 & 2.6 & Continental & 2.59 & 2.61 \\
\hline Oceania-2(42) & IV & - & 2000 & $15-44$ & 2000000 & 15 & Continental & 14.83 & 15.17 \\
\hline Africa-3(4) & \begin{tabular}{|l|} 
Mostly \\
I,II, some \\
III,IV \\
\end{tabular} & - & 2008 & $15-44$ & 221071429 & 28 & Continental & 27.98 & 28.02 \\
\hline Europe-3(4) & \begin{tabular}{|l|} 
Mostly IV \\
Some III \\
and II \\
\end{tabular} & - & 2008 & $15-44$ & 180000000 & 2 & Continental & 1.9 & 2.01 \\
\hline Asia-3(4) & I,II,III,IV & - & 2008 & $15-44$ & 980000000 & 11 & Continental & 10.99 & 11.01 \\
\hline Latin America-3(4) & $\begin{array}{l}\text { I,II, Few } \\
\text { IV }\end{array}$ & - & 2008 & $15-44$ & 136451613 & 31 & Continental & 30.97 & 31.03 \\
\hline Oceania-3(4) & IV & - & 2008 & $15-44$ & 2250000 & 8 & Continental & 7.88 & 8.12 \\
\hline Africa-4(5) & I,II,III,IV & - & 2008 & $15-44$ & 194482758 & 28 & Continental & 27.98 & 28.02 \\
\hline Asia-4(5) & I,II,III,IV & - & 2008 & $15-44$ & 975000000 & 11 & Continental & 10.99 & 11.01 \\
\hline Latin America-4(5) & $\begin{array}{l}\text { I, II, Few } \\
\text { IV }\end{array}$ & - & 2008 & $15-44$ & 133333333 & 31 & Continental & 30.97 & 31.03 \\
\hline
\end{tabular}




\begin{tabular}{|c|c|c|c|c|c|c|c|c|}
\hline Europe-4(5) & $\begin{array}{l}\text { Mostly IV } \\
\text { Some III } \\
\text { and II }\end{array}$ & 2008 & $15-44$ & 155555555 & 2 & Continental & 1.99 & 2.01 \\
\hline Oceania-4(5) & IV & 2008 & $15-44$ & 5882352 & 2.95 & Continental & 2.91 & 2.99 \\
\hline Worldwide-1(1) & I,II,III,IV & 2003 & $15-44$ & 1407142757 & 14 & Global & 13.99 & 14.01 \\
\hline Worldwide-2(42) & I,II,III,IV & 2000 & $15-44$ & 1583333333 & 75.16 & Global & 75.14 & 75.17 \\
\hline Worldwide-3(4) & I,II,III,IV & 2008 & $15-44$ & 1542857143 & 14 & Global & 13.99 & 14.01 \\
\hline Worldwide-4(5) & I,II,III,IV & 2008 & $15-44$ & 1564285714 & 14 & Global & 13.99 & 14.01 \\
\hline
\end{tabular}

Table 1. Basic description of statistics extracted on induced abortion rates

meta-analysis.

Meta-analysis of induced abortion rates from Iran

Based on the random effect model, the overall abortion rate for Iran was 26.84 per 1000 fertile women, $(\mathrm{CI}=95 \%: 23.1$ to 30.58) (Figure 7). Large amount of heterogeneity existed among statistics reported from $\operatorname{Iran}\left(Q=13147, \mathrm{df}=8, \mathrm{I}^{2}=99.94\right.$, $\mathrm{p}$-value<0.00001)

\section{DISCUSSION}

This meta-analysis shows the induced abortion rate per 1000 fertile women (aged 15-45/49) in global, continental national and local/regional level. The results revealed the high heterogeneity among different regions across the world. Midpoint induced abortion rate from 67 included statistics was 58.1 per 1000 women (13-49 years old). Overall meta-analysis reveald that the global rate of induced abortion in 2000 as the lowest followed by the national induced rate reported for Vietnam in 2001, and the national rate for Indonesia. Asia in 2008 had the highest rate of the induced abortion in global scale meta-analysis. These findings are in accordance with the achievement of population and family strategy in mid2000 in Vietnam (43). Vietnam is among the countries with completely liberal abortion law (44). The fact that induced abortion is highly restricted in Indonesia and such practice is a criminal offence and accordingly all abortion cases are officially announced as the spontaneous abortion may explain to some degree the position of this country in forest plot (45). In this context, it makes sense when some consider abortion as "confused challenge to the public health and legal systems of Indonesia” (46) .

Looking at forest plot of induced abortion in continental level, it is evident that Africa and Latin America have similarity. Asia in 2000, 2003, and 2008 has been nearly overlapped with the summary line. Based on the meta-analysis, Europe and Latin America have been located in the same position in 2000 while the Latin America has moved in opposite side in 2003 and 2008. This may be attributed to the major changes happened in the region after 2000. For instance, Portugal reformed their abortion law significantly in 2007 while it was more restrictive earlier. Similarly, Switzerland made the abortion law more liberated in 2002. In addition, France extended the gestational period during which the abortion is legal and made the abortion more accessible. Denmark and Sweden also removed restriction of non-residents for accessing to abortion in these countries (47).
Meta-analysis in the national level highlighted the difference of Indonesia and Vietnam with others. Looking at the national level analysis, Indonesia appears to be a specific case and its situation remains similar in both global and national meta-analysis. This country is among those with highly restricted abortion law. Compared with the global level, the position of Vietnam has moved closer to the Indonesia in the national level analysis. In contrast with Indonesia, Vietnam has completely liberal abortion law. This implies there might be no association between the legality of abortion and its incidence.

Although, Indonesia, Vietnam, and Philippines from Asia and Peru from Latin America all are at the same side of the summary line, Philippines and Peru are relatively close to the summary line.

Based on of meta-analysis in regional or local level, it is evident that abortion rate of Rural Vietnam has overlapping with the summary line in forest plot. Iranian Cities (except for one from Kermanshah), Abbottabad and Bahawalpur from Pakistan have been located in left side of the summary line. Other cities have been located in opposite side of the summary line. Moreover, Tehran in 2008 has the highest rate in the plot and it appears to have similar situation with Bahawalpur from Pakistan.

High heterogeneity observed among different locations can be justified with socio-demographic, socioeconomic, or even socio-cultural characteristics of those places or changes in these characteristics. In addition, this heterogeneity might be originated from the differences in reporting induced abortions rates and its reliability due to different laws, beliefs, religion, ideologies, norms, or ethical principles in different places. For instance, childbearing outside of wedlock is not acceptable or legitimate in some societies while it is acceptable in others. Variety of data sources can also be another cause of the heterogeneity $(48,49)$.

Changes in view of women on the family size, economic pressures, late marriage, access to population and family planning services including providing population with appropriate education, lack of appropriate social policies for promoting a mother and child friendly society as well as the women quest for achieving social and economic equality by woman can also influence the induced abortion rate (50-52). 
Studies

Overall

- Rwanda-2009

- Abbottabad, Pakistan-2006(Jan)-2007(Dec)

- Peru-2005(Sep-Dec)

- Rural Vietnam-1994-2004

- Athens, Greece-2005-2008

- Mexico-1990-2006

- Ethiopia-2008

- Pakistan1-2008

- Worldwide-2003

- Africa-2003

- Asia-2003

- Europe-2003

- Latin America-2003

- North America-2003

- Oceania-2003

- Guatmala-2003

- Nigeria-2002

- Uganda-2003

- Philippines1-2000

- Burkino Faso-2008

- Worlwide-2000

- Africa-2000

- Asia-2000

- Europe-2000

- Latin America-2000

- Oceania-2000

- Worldwide1-2008

- Africa1-2008

- Europe1-2008

- Asia1-2008

- Latin America1-2008

- Oceania1-2008

- South Korea-2005

- Vietnam-2001

- Rural Ghana-1999(Feb-Jul)

- Rural Community in South India-1996

- Romania-2001(Nov)

- Urban Tanzania-2003

- Urban Tanzania-2006

- Bahawalpur, India

- Pakistan- Jan 2005-Dec 2005

- Lusaka, Zambia- 2005(4 months)

- Cartagena, Columbia-2005

- Cartagena, Columbia-2006

- Cartagena, Columbia-2007

- Karachi, Pakistan-(2005-2009)

- Worldwide2-2008

- Africa2-2008

Asia2-2008

- Latin America2-2008

- Europe2-2008

- Oceania2-2008

- Cambodia-2005

- Indonesia-2000

- Uganda-2002

- Pakistan-2002

- Guatemala-2003

- Philippines-2000

- Tehran, Iran-(2008)

- Tehran, Iran-(July 2003- Jan 2004)

- Isfahan, Iran-(2003-2004)

- Tehran-Iran(2009)

- Iran(2000)

- Shiraz, Iran(2001)

Kermanshah, Iran (2004)

- Tehran, Iran(1991-1995)

- Kermanshah, Iran(1992-2002)
Estimate (95\% C.I.)

$0.05810(0.05516,0.06104)$

$0.05870(0.05573,0.06166)$

$0.05824(0.05528,0.06120)$

$0.05716(0.05419,0.06012)$

$0.05687(0.05391,0.05983)$

$0.05764(0.05470,0.06058)$

$0.05853(0.05557,0.06150)$

$0.05873(0.05576,0.06170)$

$0.05861(0.05564,0.06157)$

$0.05943(0.05638,0.06248)$

$0.05852(0.05557,0.06147)$

$0.05950(0.05645,0.06256)$

$0.05941(0.05639,0.06242)$

$0.05855(0.05560,0.06151)$

$0.05952(0.05650,0.06255)$

$0.05910(0.05614,0.06207)$

$0.05871(0.05575,0.06168)$

$0.05661(0.05366,0.05955)$

$0.05817(0.05520,0.06113)$

$0.05865(0.05569,0.06162)$

$0.05870(0.05573,0.06166)$

$0.05027(0.04830,0.05223)$

$0.05873(0.05576,0.06169)$

$0.05954(0.05649,0.06260)$

$0.05941(0.05639,0.06242)$

$0.05940(0.05639,0.06241)$

$0.05888(0.05591,0.06184)$

$0.05948(0.05642,0.06254)$

$0.05853(0.05558,0.06148)$

$562,0.06259)$

$0.05956(0.05650,0.06262)$

$0.05850(0.05555,0.06145)$

$0.05900(0.05604,0.06197)$

$0.05960(0.05656,0.06264)$

$0.05237(0.04941,0.05534)$

$0.05468(0.05173,0.05764)$

$0.05767(0.05473,0.06062)$

$0.05842(0.05546,0.06137)$

$0.05604(0.05310,0.05899)$

$0.05680(0.05385,0.05974)$

$0.05913(0.05616,0.06210)$

$0.05769(0.05474,0.06063)$

$0.05784(0.05490,0.06078)$

$(0.05257,0.05849)$

$0.05556(0.05260,0.05853)$

$0.05571(0.05275,0.05868)$

$0.05784(0.05490,0.06078)$

$0.05949(0.05643,0.06255)$

$0.05855(0.05560,0.06150)$

$0.05956(0.05650,0.06261)$

$0.05850 \quad 10.05555,0.10$.

$0.05850(0.05555,0$.

$647,0.06252$

$0.05910(0.05614,0.06207)$

$0.05899(0.05603,0.06196)$

$0.05240(0.04946,0.05534)$

$0.05885(0.05589,0.06182)$

$0.05905(0.05608,0.06202)$

0.06056

$0.05909(0.05612,0.06206)$

$0.05905(0.05608,0.06202)$

$0.05759(0.05463,0.06055)$

$0.05774(0.05479,0.06068)$

$0.05903(0.05607,0.06200)$

$0.05902(0.05605,0.06199)$

$0.05847(0.05551,1000$

.06143

$0.05912(0.05615,0.06209)$

$0.05773(0.05477,0.06068)$

$0.05798(0.05501,0.06095)$

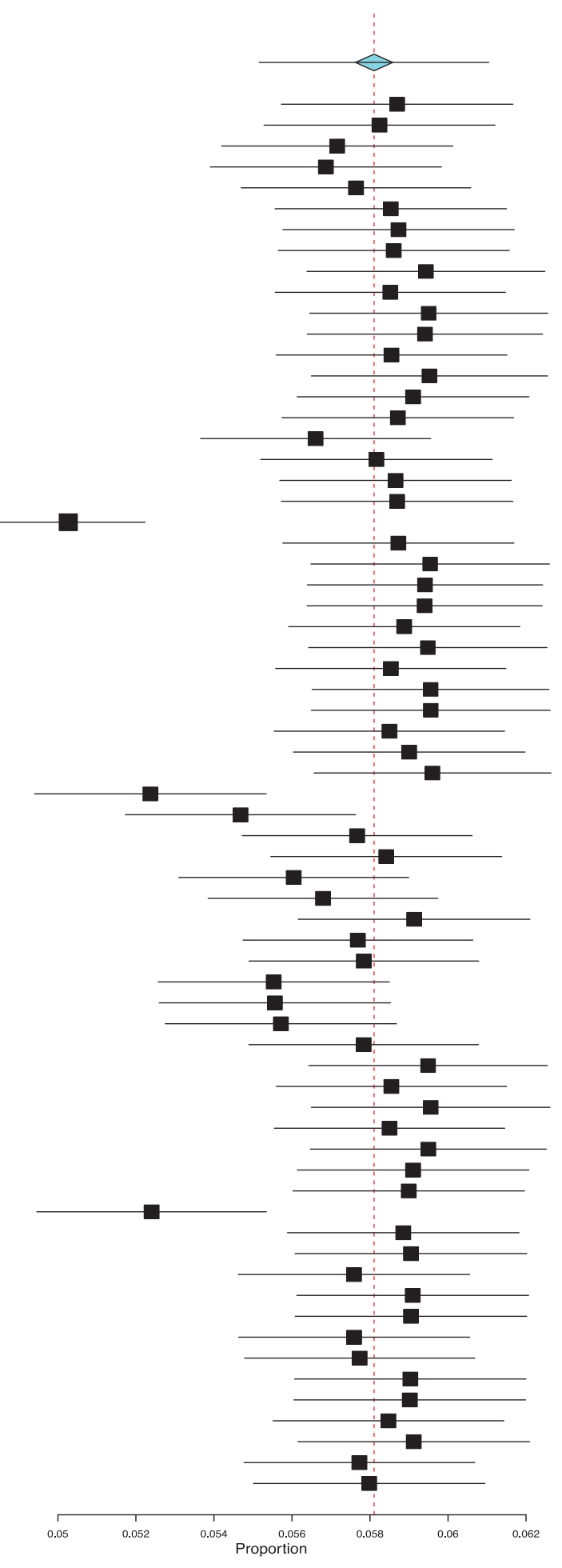

Figure 2. Meta-analysis of overall abortion rates based on random effect model

\section{CONCLUSION}

Induced abortion is a major public health problem that occurs worldwide whether under of legal restriction or freedom, and it remains as reproductive health concern globally. To eliminate the need for induced abortion is at the core of any effort for preventing this issue. Regardless of the region, availability of appropriate choices for women in reproductive age is vital. Policies should support these choices and authorities should put appropriate and effective mechanisms in place to make these choices feasible. The first high propriety 


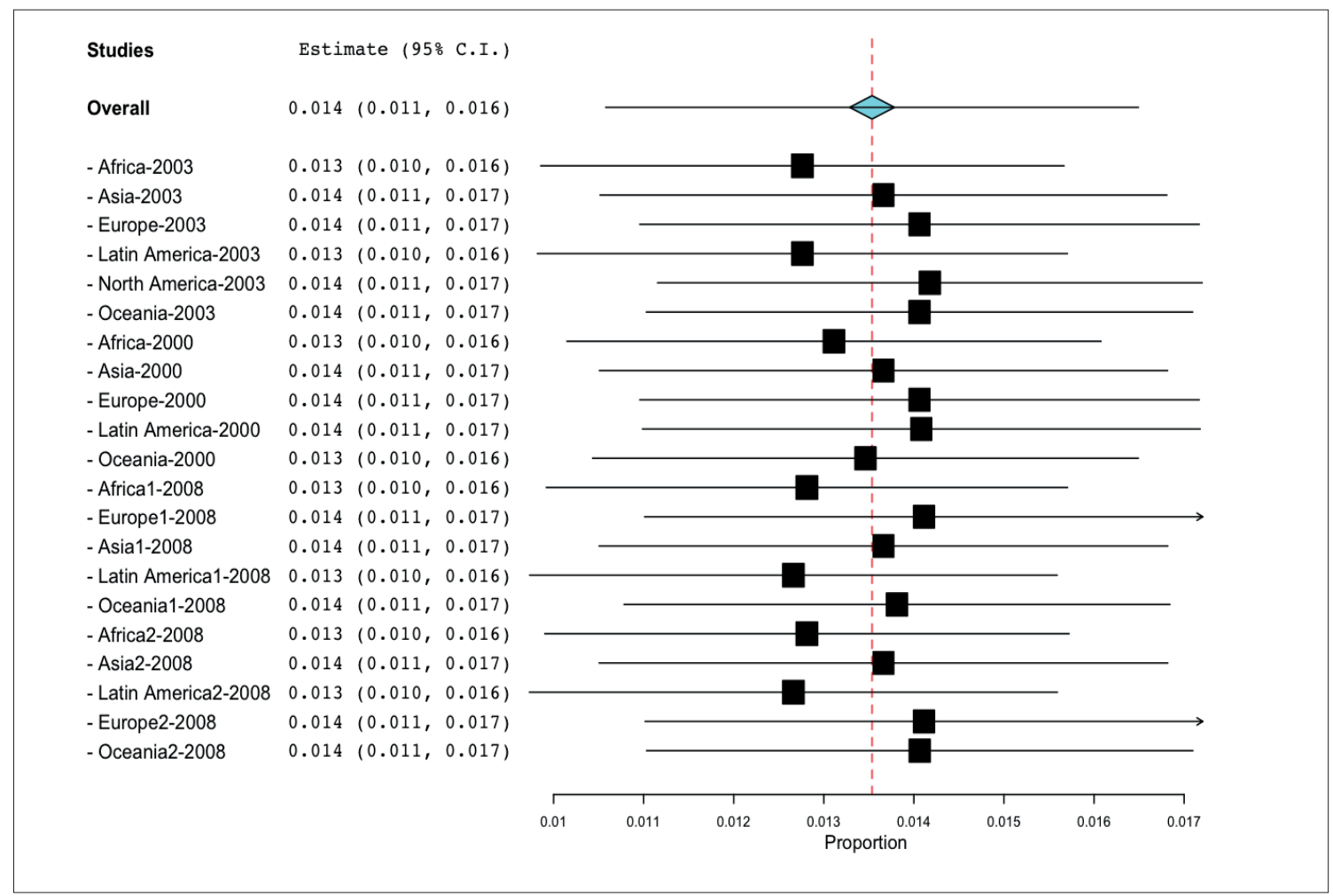

Figure 3. Meta-analysis of abortion rates in Continental level based on random effect model

Studies
Overall
- Rwanda-2009
- Abbottabad, Pakistan-2006(Jan)-2007(Dec)
- Peru-2005(Sep-Dec)
- Rural Vietnam-1994-2004
- Athens, Greece-2005-2008
- Mexico-1990-2006
- Ethiopia-2008
- Pakistan1-2008
- Guatmala-2003
- Nigeria-2002
- Uganda-2003
- Philippines1-2000
- Burkino Faso-2008
- South Korea-2005
- Vietnam-2001
- Rural Ghana-1999(Feb-Jul)
- Rural Community in South India-1996
- Romania-2001(Nov)
- Urban Tanzania-2003
- Urban Tanzania-2006
- Bahawalpur, Pakistan
- Hyderabad, Pakistan- Jan 2005-Dec 2005
- Lusaka, Zambia- 2005(4 months)
- Cartagena, Columbia-2005
- Cartagena, Columbia-2006
- Cartagena, Columbia-2007
- Karachi, Pakistan-(2005-2009)
- Cambodia-2005
- Indonesia-2000
- Uganda-2002
- Pakistan-2002
- Guatemala-2003
- Philippines-2000
- Tehran, ran-(2008)
- Tehran, Iran-(July 2003- Jan 2004)
- Isfahan, Iran-(2003-2004)
- Tehran-Iran(2009)
- Iran(2000)
- Shiraz, Iran(2001)
- Kermanshah, Iran (2004)
- Tehran, Iran(1991-1995)
- Kermanshah, Iran(1992-2002)

Estimate (958 C.I.)

$0.101(0.095,0.106)$ $0.103(0.098,0.108)$ $0.102(0.097,0.107)$ $0.100(0.095,0.106)$
$0.100(0.094,0.105)$ $0.099(0.094,0.105)$ $0.102(0.096,0.107)$ $0.103(0.098,0.108)$ $0.102(0.097,0.107)$ $0.103(0.098,0.108)$ $0.097(0.092,0.102)$ $0.102(0.096,0.107)$ $0.103(0.097,0.108)$ 0.111 (0.108, 0.108$)$ $0.092(0.086,0.097)$ $0.094(0.088,0.099)$ $0.100(0.095,0.105)$ $0.102(0.097,0.108)$ $0.095(0.090,0.101)$ $0.097(0.092,0.102)$ $0.104(0.098,0.109)$ $0.100(0.094,0.105)$ $0.100(0.095,0.105)$ $0.097(0.092,0.103)$ $0.097(0.092,0.103)$ $0.098(0.092,0.103)$ $0.100(0.055,0.105)$ $0.104(0.098,0.109)$ $0.083(0.079,0.088)$ $0.108(0.102,0.114)$ $0.101(0.095,0.106)$ $0.108(0.102,0.115)$ $0.104(0.098,0.109)$ $0.101(0.095,0.106)$ $0.100(0.095,0.106)$ $0.104(0.098,0.109)$ $0.105(0.099,0.110)$ $0.102(0.097,0.108)$
$0.104(0.098,0.109)$ $0.104(0.098,0.109)$
$0.101(0.095,0.106)$
$0.102(0.096,0.107)$ $0.102(0.096,0.107)$

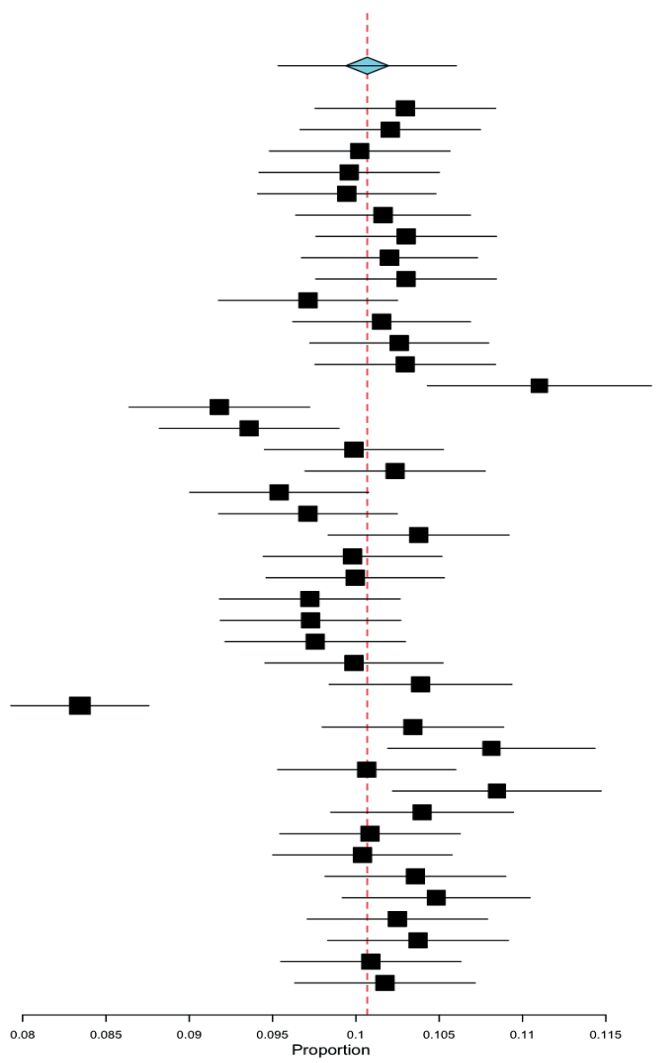




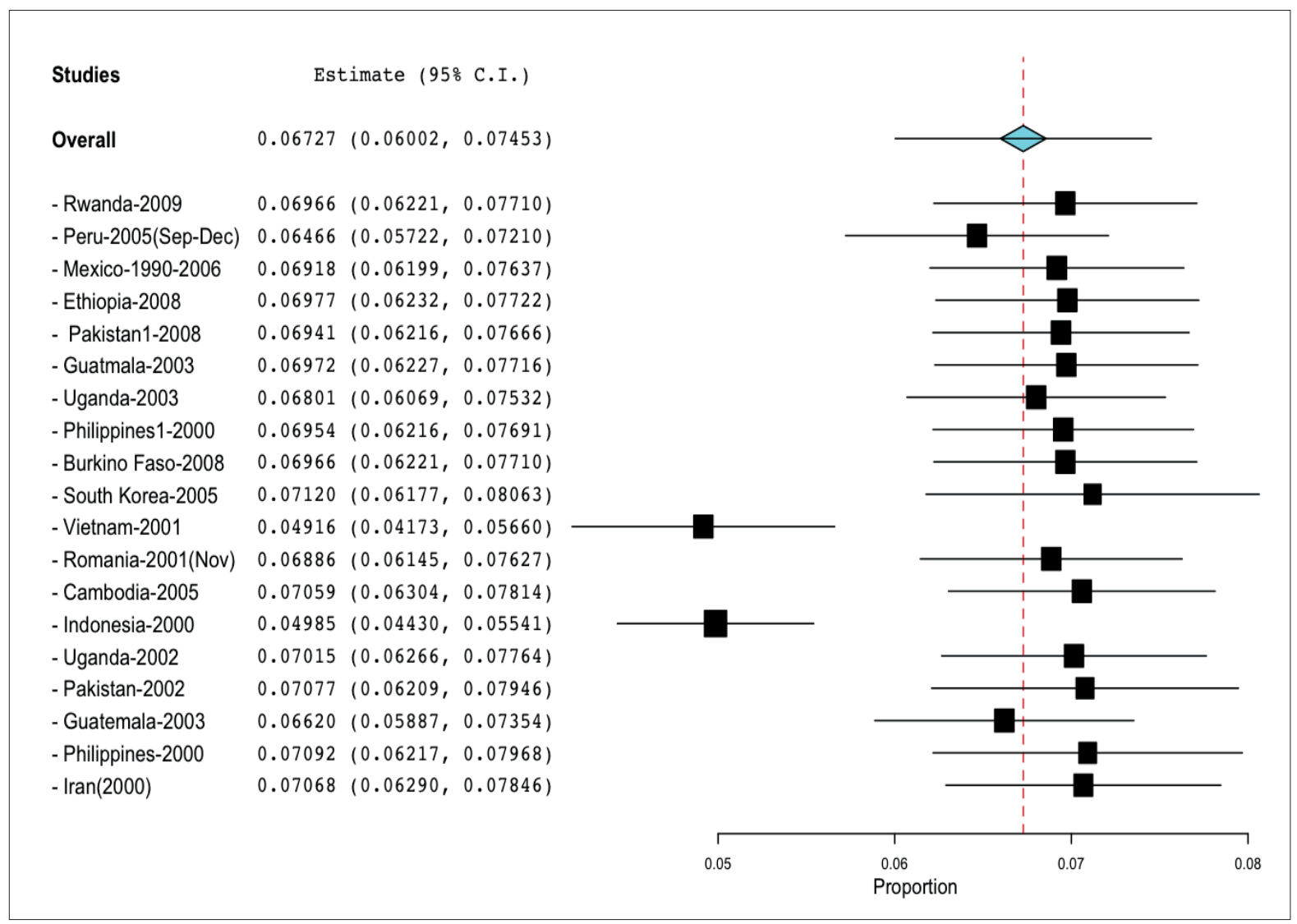

Figure 5. Meta-analysis of the abortion rates in National level based on random effect model

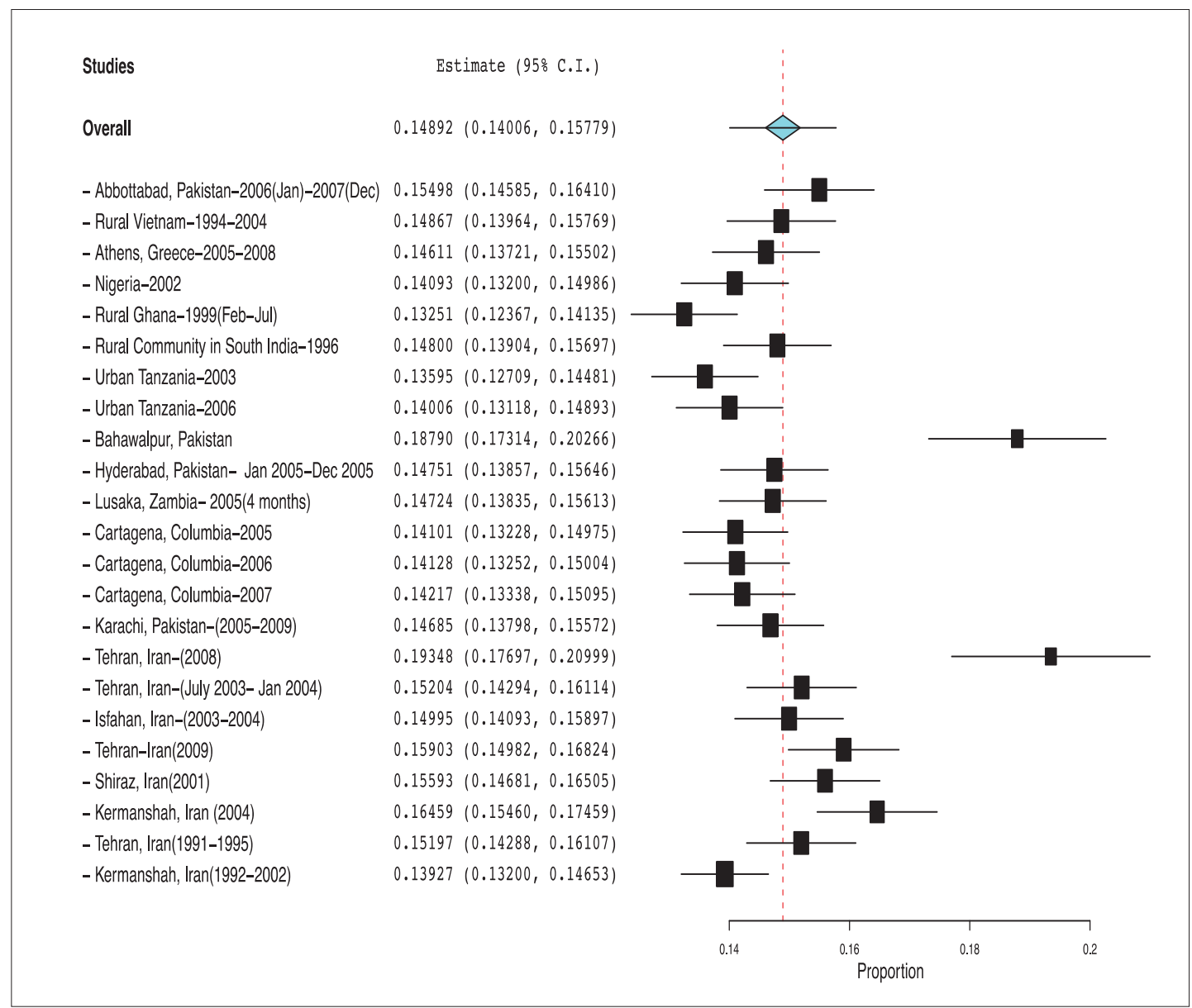

Figure 6. Meta-analysis of abortion rates in regional or local level based on random effect model 
Studies

Estimate (95\% C.I.)

Overall $\quad 0.02684(0.02310,0.03058)$

- Tehran, Iran-(2008)

$0.04778(0.03191,0.06365)$

- Tehran, Iran-(July 2003- Jan 2004) $0.02209(0.01825,0.02593)$

- Isfahan, Iran-(2003-2004)

$0.02557(0.02182,0.02933)$

- Tehran-Iran(2009)

$0.03082(0.02675,0.03489)$

- Iran(2000)

- Shiraz, Iran(2001)

- Kermanshah, Iran (2004)

- Tehran, Iran(1991-1995)

- Kermanshah, Iran(1992-2002)
$0.04771(0.03135,0.06406)$

$0.02672(0.02288,0.03055)$

$0.03204(0.02794,0.03614)$

$0.02426(0.02046,0.02806)$

$0.00839(0.00665,0.01013)$

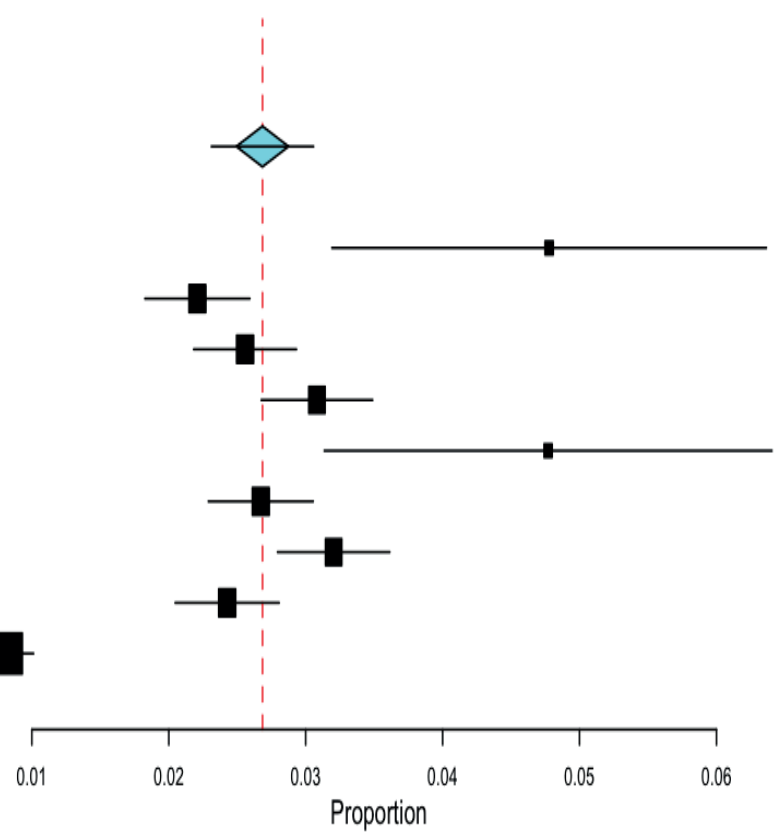

Figure 7. Meta-analysis of abortion rates in Iran based on random effect model

option should be to prevent unwanted pregnancies through educational and contraceptive interventions. The second high priority is timely and easy provision of safe abortion services for all those with unintended pregnancy.

\section{REFERENCES}

1. Sedgh G, Henshaw S, Singh S, Ahman E, Shah I. Induced abortion: estimated rates and trends worldwide Lancet. 2007; 370(9595): 1338-45.

2. Sedgh G, Henshaw S, Singh S, Bankole A, Drescher J. Legal abortion worldwide: incidence and recent trends. Perspect Sex Reprod Health. 2007; 39(4): 216-25.

3. Grimes D, Benson J, Singh S, Romero M, Ganatra B, Okonofua F, Shah I. Unsafe abortion: the preventable pandemic. Lancet. 2006; 368(9550): 1908-19.

4. World Health Organization. Unsafe abortion: global and regional estimates for the incidence of unsafe abortion and associated mortality in 2008. WHO, Geneva, 2011.

5. Sedgh G, Singh S, Shah I, Ahman E, Henshaw S, Bankole A. Induced abortion: incidence and trends worldwide from 1995 to 2008. Lancet. 2012; 379(9816): 625-32.

6. Singh S, Prada E, Mirembe F, Kiggundu C. The incidence of induced abortion in Uganda. Int Fam Plan Perspect. 2005; 31(4): 183-91.

7. Basinga P, Moore A, Singh S, Carlin E, Birungi F, Ngabo F. Abortion Incidence and Postabortion Care in Rwanda. Studies in Family Planning. 2012; 43: 11-20.

8. Wallace B, Dahabreh I, Trikalinos T, Lau J, Trow P, Schmid C. Closing the gap between methodologists and end-users: $\mathrm{R}$ as a computational back-end. Journal of Statistical Software. 2012; 49(5): 1-15.

9. Juarez F, Singh S, Garcia S, Olavarrieta C. Estimates of induced abortion in Mexico: what's changed between 1990 and 2006? International Family Planning Perspectives. 2008; 34(4): 158 168.
10. Bernabe-Ortiz A, White P, Carcamo C, Hughes J, Gonzales M, Garcia P, Garnett G, Holmes K. Clandestine induced abortion: Prevalence, incidence and risk factors among women in a Latin American country. CMAJ. 2009; 180(3): 298-304.

11. Singh S, Fetters T, Gebreselassie H, Abdella A, Gebrehiwot Y, Kumbi S, Audam S. The estimated incidence of induced abortion in Ethiopia, 2008. International Perspectives on Sexual and Reproductive Health. 2010; 36(1): 16-25.

12. Sathar Z, Singh S, Fikree F. Estimating the incidence of abortion in Pakistan. Studies in Family Planning. 2007; 38(1): 11-22.

13. Singh S, Prada E, Kestler E. Induced abortion and unintended pregnancy in Guatemala. International family planning perspectives. 2006; 32(3): 136-45.

14. Juarez F, Cabigon J, Singh S, Hussain R. The incidence of induced abortion in the Philippines: current level and recent trends. International Family Planning Perspectives. 2005; 31(3): 140-9.

15. Sedgh G, Rossier C, Kabore I, Bankole A, Mikulich M. Estimating abortion incidence in Burkina Faso using two methodologies. Studies in Family Planning. 2011; 42(3): 147-54.

16. Ahn H, Seol H, Lim J, Hong S, Lee S, Park M, Kim S, HJ K. Estimates of induced abortion in South Korea: Health facilities survey. Journal of Obstetrics and Gynaecology Research. 2012; 38(1): 324-8.

17. Teerawichitchainan B, Amin S. The role of abortion in the last stage of fertility decline in Vietnam. International Family Planning Perspectives. 2010; 36(2): 80-9.

18. Johnson B, Horga M, Fajans P. A strategic assessment of abortion and contraception in Romania. Reproductive Health Matters. 2004; 12(24): 184-94.

19. Fetters T, Vonthanak S, Picardo C, Rathavy T. Abortion-related complications in Cambodia. BJOG: an internationl Journal of Obstetrics and Geneacology. 2008; 115(8): 957-68.

20. Sedgh G, Ball H. Abortion in Indonesia. Issues Brief (Alan Guttmacher Inst). 2008; Sep(2): 1-6. 
21. Singh S. Hospital admissions resulting from unsafe abortion: estimates from 13 developing countries. Lancet. 2006; 368(9550): 1887-92.

22. Erfani A, McQuillan K. Rates of Induced Abortion in Iran: The Roles of Contraceptive Use and Religiosity. Studies in Family Planning. 2008; 39(2): 111-22.

23. Fawad A, Naz H, Khan K, Azizun N. Septic induced abortions. J Ayub Med Coll Abbottabad. 2008; 20(4): 145-8.

24. Graner S, Klingberg-Allvin M, Phuc H, Krantz G, Mogren I. The panorama and outcomes of pregnancies within a well-defined population in rural Vietnam 1999-2004. Int J Behav Med. 2009; 16(3): 269-77.

25. Drakakis P, Sotiropoulou M, Goumalatsos N, Stefanidis K, Blanas K, Vlismas A, Loutradis D, Antsaklis A. Contraception and induced abortions inwomen above 39 years old. A retrospective study. Maturitas. 2009; 63(Supplement 1): S65.

26. Murray N, Winfrey W, Chatterji M, Moreland S, Dougherty L, Okonofua F. Factors related to induced abortion among young women in Edo State, Nigeria. Studies in Family Planning. 2006; 37(4): 251-68.

27. Geelhoed D, Nayembil D, Asare K, Schagen van Leeuwen JH, van Roosmalen J. Contraception and induced abortion in rural Ghana. Tropical Medicine \& International Health. 2002; 7(8): 708-16.

28. Varkey P, Balakrishna P, Prasad J, Abraham S, Joseph A. The reality of unsafeabortion in a rural community in South India. Reproductive Health Matters. 2000; 8(16): 83-91.

29. Rasch V, Kipingili R. Unsafe abortion in urban and rural Tanzania: method, provider and consequences. Tropical Medicine \& International Health. 2009; 14(9): 1128-33.

30. Shams-Un-Nisa, AM M, Sadaf-Un-Nisa. Maternal complications attributed to induced abortion. Medical Forum Monthly. 2008; 19(10): 10-15.

31. Shaikh Z, Abbassi R, Rizwan N, Abbasi S. Morbidity and mortality due to unsafe abortion in Pakistan. International Journal of Gynecology \& Obstetrics. 2010; 110(1): 47-9.

32. Dahlback E, Maimbolwa M, Yamba C, Kasonka L, Bergstrom S, Ransjo- Arvidson A. Pregnancy loss: spontaneous and induced abortions among young women in Lusaka, Zambia. Culture, health \& sexuality. 2010; 12(3): 247-62.

33. Monterrosa-Castro A, Paternina-Caicedo A, Alcalá-Cerra G. Induced abortion in Cartagena, Colombia: estimation using abortion incidence complications methodology. Rev Salud Publica (Bogota). 2011; 13(2): 253-61.

34. Shah N, Hossain N, Noonari M, Khan N. Maternal mortality and morbidity of unsafe abortion in a university teaching hospital of Karachi, Pakistan. J Pak Med Assoc. 2011; 61(6): 582-6.
35. Erfani A. Induced Abortion in Tehran, Iran: Estimated Rates and Correlates. International Perspectives on Sexual and Reproductive Health. 2011; 37(3): 134-42.

36. Nojoumi M, Akbarian A, Ashory-Moghadam S. Burden of abortion: induced and spontaneous. Archives of Iranian Medicine. 2006; 9(1): 39-45.

37. Majlessi F, Forooshani A, Shariat M. Prevalence of induced abortion and associated complications in women attending hospitals in Isfahan. Eastern Mediterranean Health Journal. 2008; 14(1): 103-9.

38. Zare N, Dastoori P. Estimating the proportion of illegal abortion in 15-49 year-old women by randomized response technique. Medical Journal of Tabriz University of Medical Sciences. 2004; (61): 36-9.

39. Kookooyi F, Heidarpour S. Epidemiological study of abortion in pregnant women admitted to Motazedi hospital in Kermanshah. Fertility and Infertility Medicine Quarterly. 2004.

40. Amid V, Moeini A. Study of induced and induced abortion cases admitted to Rueintan Arash Hospital(1992-1995). Medical Journal of Forensic Medicine. 1999; 5(16): 16-25.

41. Malek-Khosravi S, Kaboudi B. Abortion prevalence and it's mortality effects in Mo'tazedi hospital of Kermanshah. Behbood. 2005; 9(3).

42. Ahman E, Shah I. Unsafe Abortion: Worldwide Estimates for 2000. Reproductive Health Matters. 2002; 10(19): 13-17.

43. Vietnam Population strategy 2001-2010.

44. World abortion law.

45. Nations U. Abortion policies: a global review. Vol II: United Nations Publications, 2001.

46. Whittaker A. Abortion in Asia: Local Dilemmas, Global Politics. Berghahn Books, 2013.

47. Boland R, Katzive L. Developments in Laws on Induced Abortion: 1998-2007. International Perspectives on Sexual and Reproductive Health. 2008; 34(3): 110-20.

48. Llorente-Marron M, Diaz-Fernández M, Mendez-Rodriguez P. Contextual determinants of induced abortion: a panel analysis. Revista de Saude Publica. 2016; 50.

49. Malwade Basu A. The sociocultural and political aspects of abortion: global perspectives. USA: Greenwood, 2003.

50. Behjati Ardakani Z, Akhondi M, Sadeghi M, Sadri-Ardekani H. The necessity of a comprehensive study on abortion in Iran. Journal of Reproduction and Infertility. 2005; 6(4): 299-320.

51. Waylen G, Celis K, Kantola J, Weldon S. The Oxford Handbook of Gender and Politics. Oxford University Press, 2013.

52. Kennedy P, Kodate N. Maternity services and policy in an international context: risk, citizenship and welfare regimes. London and Newyork: Routledge Taylor \& Francis Group, 2015. 